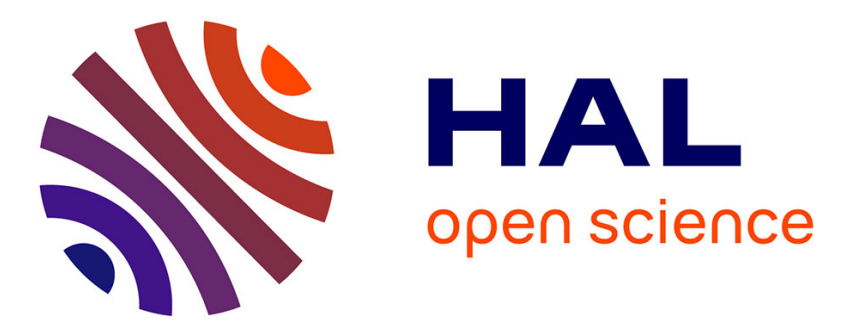

\title{
Photocatalytic oxidation of VOCs at ppb level using a closed-loop reactor: The mixture effect
}

Valérie Hequet, C. Raillard, O. Debono, F. Thevenet, N. Locoge, Laurence Le Coq

\section{- To cite this version:}

Valérie Hequet, C. Raillard, O. Debono, F. Thevenet, N. Locoge, et al.. Photocatalytic oxidation of VOCs at ppb level using a closed-loop reactor: The mixture effect. Applied Catalysis B: Environmental, 2018, 226, pp.473 - 486. 10.1016/J.APCATB.2017.12.041 . hal-01700177

\section{HAL Id: hal-01700177 \\ https://hal.science/hal-01700177}

Submitted on 21 Aug 2019

HAL is a multi-disciplinary open access archive for the deposit and dissemination of scientific research documents, whether they are published or not. The documents may come from teaching and research institutions in France or abroad, or from public or private research centers.
L'archive ouverte pluridisciplinaire HAL, est destinée au dépôt et à la diffusion de documents scientifiques de niveau recherche, publiés ou non, émanant des établissements d'enseignement et de recherche français ou étrangers, des laboratoires publics ou privés. 


\title{
Photocatalytic oxidation of VOCs at ppb level using a closed-loop reactor: The mixture effect
}

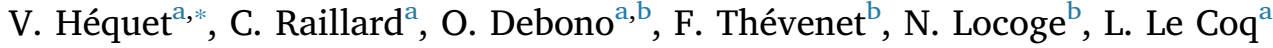 \\ a IMT Atlantique, GEPEA, UMR CNRS 6144, F-44307 Nantes, France \\ b IMT Lille Douai, SAGE, Université de Lille, F-59500 Douai, France
}

Keywords:

Photocatalysis

VOC mixture

Toluene

n-decane

TCE

ppb level

Indoor air

Reaction intermediates

Multi-pass closed-loop reactor

\begin{abstract}
A B S T R A C T
An investigation of the photocatalytic degradation of indoor air model pollutants: toluene, $n$-decane and trichloroethylene (TCE), as single contaminants and in a mixture is proposed. The degradation of these contaminants was performed in a continuous closed-loop reactor operating in recirculation mode. Degradations were conducted at ppb level concentrations and under humid conditions $(\mathrm{RH}=50 \%)$ in order to be closer to real applications of photocatalytic oxidation (PCO) systems developed for indoor air quality improvement. Accurate analytical methods were developed to identify and quantify the majority of the potential formed intermediates. Kinetic constants and the time constant of degradation were obtained for the model pollutants. Under these conditions, the degradation of the three VOCs in a mixture did not really show a decrease in the kinetic rates. Toluene and decane degradations were slightly slowed down when they were in a mixture but no significant interference was demonstrated with TCE. The intermediates formed during the PCO of the mixture of VOCs were the same as those identified during single degradation, leading to the hypothesis of few interactions between them. Only the formation and degradation of secondary intermediates, mostly composed of aldehydes, were time delayed. The total VOC concentration may lead to a competitive adsorption that seemed more sensitive for the last formed oxygenated intermediates. This investigation points out the need to always monitor the last formed aldehyde intermediates. Monitoring acetaldehyde and formaldehyde enables an evaluation of the efficiency and a better design of future PCO systems for indoor applications.
\end{abstract}

\section{Introduction}

In industrialized and developed countries, people spend considerable time indoors. In these environments, concentrations of pollutants may reach values 5 times higher than outdoors, and sometimes even 100 times higher [1]. Consequently, indoor air pollutants may impact human health, comfort and productivity. Volatile Organic Compounds (VOCs) are among the most abundant chemical pollutants in indoor air. Some of them trigger the sick building syndrome (SBS) including mucous membrane irritation, headache and fatigue; others are known to be carcinogenic (e.g., formaldehyde, acrolein). Millions of people are currently suffering from the consequences of poor indoor air quality [2]. Sources of VOCs in indoor environments include building materials (e.g., paint, sealants, flooring, furniture, and upholstery), products (e.g., cleaning materials, solvents, and cooking fumes) and occupant activities. They are also attributed to outdoor air quality.

Several technologies such as adsorption, non-thermal plasma or photocatalytic oxidation (PCO) are available for the fast and economical removal of VOCs from indoor air. In particular, PCO is a cost- effective method, both efficient and simple, which does not produce waste. It is therefore attractive for removing VOCs from indoor air [3]. It can decompose a broad range of VOCs encompassing multiple chemical functionalities [4]. PCO potentially mineralizes VOCs into inorganic compounds such as $\mathrm{CO}_{2}$ and water. However, there are still several points to be addressed for the safe development of PCO systems:

i.) Most of the studies devoted to indoor pollution have dealt with high pollutant concentrations, typically ppmv levels, whereas indoor air concentrations are three orders of magnitude lower: ppbv level [5]. Total concentrations of the main indoor contaminants, including alkanes and aromatic hydrocarbons, are measured at few hundreds of ppbv. Thus, an efficient investigation of PCO for indoor air treatment requires the use of ppbv levels of VOCs in order to mimic real indoor air conditions.

ii.) Moreover, to date few studies have been performed with pollutants in a mixture and at ppbv level [4,6-8]. Little information can be found in the literature regarding the possible influence of the presence of co-pollutants when evaluating the degradation rate of 
1.Photocatalytic unit

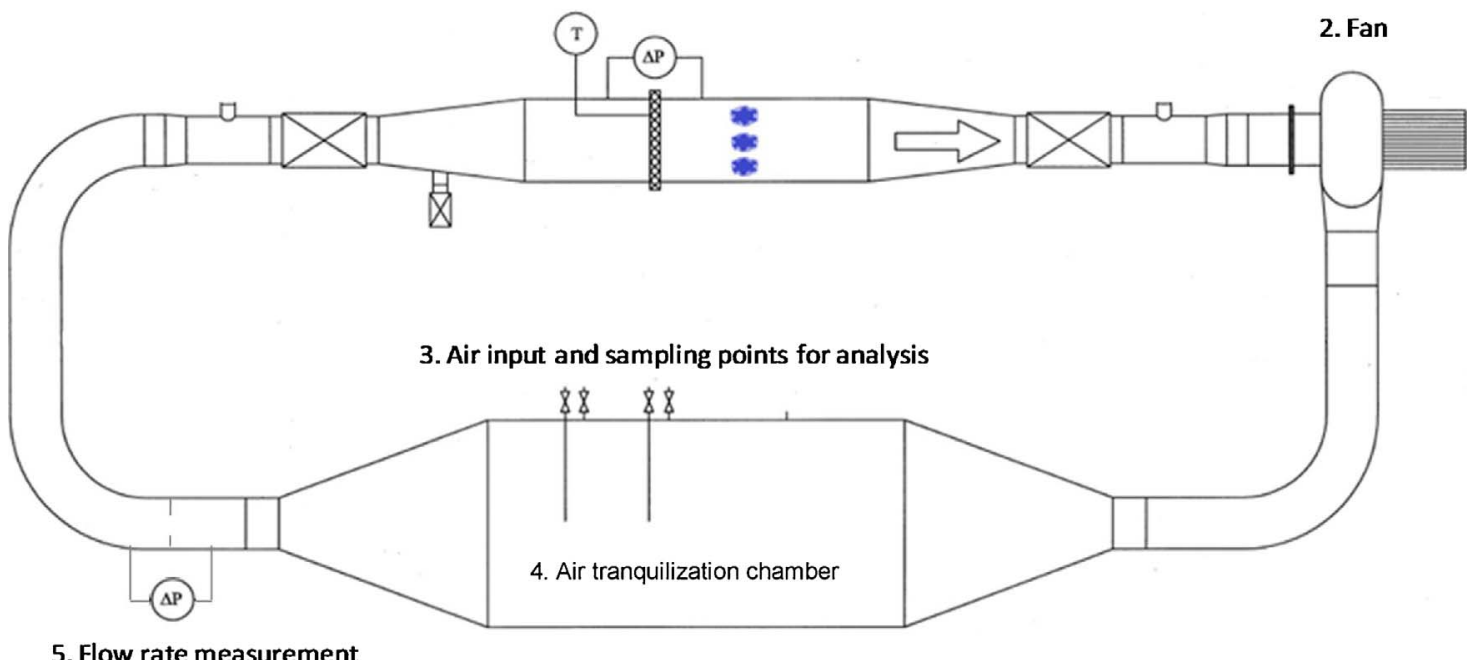

5. Flow rate measurement

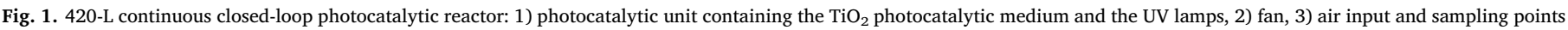
for analysis, 4) air tranquilization chamber, 5) flow rate measurement.

model pollutants [9]. Although recent standards (AFNOR) [10] have considered evaluating the performance of PCO systems on several major pollutants, no comparisons are available on the degradation rate of pollutants measured individually or in a mixture. Thus, the question of the transposition of phenomena reported at ppmv level regarding the removal kinetics of individual compounds to ppbv level regarding a mixture of VOCs remains unanswered. There is still a need to be closer to realistic conditions [7].

iii.) Before mineralization and the corresponding formation of $\mathrm{CO}_{2}$, VOCs are oxidized step by step into reaction intermediates, which could be less sensitive to photocatalytic oxidation, thus potentially forming organic by-products. This phenomenon has been observed during the PCO of single or multi-component mixtures [11-14]. It thus appears necessary to measure intermediates and characterize the possible reaction pathways and the progress of the oxidation reaction.

In order to answer the above-mentioned questions, this work focused on the PCO of three indoor air model VOCs. PCO degradation of toluene, $n$-decane and trichloroethylene (TCE) was performed on single compounds and then on a mixture. Alkanes and aromatic hydrocarbons are common indoor contaminants. The main sources of toluene in indoor air are painting, tobacco smoke and outdoor pollution in urban areas [15]. Toluene is one of the most investigated model pollutants in photocatalytic oxidation studies. It is recommended as a model pollutant for photocatalytic system performance evaluation in the AFNOR standard XP-B44-013 [10]. Decane can be considered one of the major alkanes monitored in indoor air [16]. It is mainly attributed to solvents, cleaning materials and some building materials. Decane can be considered a model pollutant of long-chain alkanes such as heptane, which is a recommended reference pollutant for PCO system evaluation in the XP B44-013 French standard too. Along with alkanes, chlorinated hydrocarbons are considered indoor contaminants. Trichloroethylene (TCE) is one of the most common and is also carcinogenic. This molecule is well-known as a metal degreaser in the aviation and microelectronics industries, but is also a dry cleaning agent and may accumulate in public or domestic environments; homes, offices, schools, and shopping malls $[17,18]$. Thus, with the objective of highlighting the behavior of these three model compounds during PCO degradation, this work focused on the identification of potential reaction intermediates during degradation of single contaminants compared to degradation of their mixture. In order to be closer to real indoor air conditions, degradations were carried out at ppbv level. This work is the continuation of a preliminary study performed in a 120-L Pyrex batch reactor, which improved the understanding of intermediate formation during the PCO of toluene and $n$-decane $[13,14]$. It is also related to a recently published work in which the degradation of a ternary mixture of toluene, $n$-decane and TCE was performed and compared to the degradation of the single compounds at ppbv level [9]. This study was also conducted in the 120-L Pyrex batch reactor and focused on understanding the mechanisms occurring in the degradation of single components or a mixture. The present paper is also dedicated to the comparison of the individual degradation kinetics of the three molecules, the intermediates that are formed and their behaviors when these molecules are in a mixture. Experiments were again performed at ppbv levels but using a continuous closed-loop photocatalytic reactor in recirculation mode. This reactor avoids mass transfer limitation by optimizing the contact between the pollutants and the photocatalytic material $[19,20]$. It also better represents PCO systems developed in dynamic mode, where the air flow rate through the PCO system is forced, and is therefore more realistic regarding the PCO air purifiers or PCO devices implemented in heating, ventilation and air conditioning (HVAC) systems of buildings.

\section{Experimental}

\subsection{VOC generation}

Depending on the VOCs that were introduced into the photocatalytic reactor, two different methods of generation were employed. For instance, toluene and TCE were injected into the reactor as a vapor by means of a $50-\mathrm{mL}$ airtight syringe through a septum. The vapors were prepared by evaporating liquid toluene or TCE in a $285-\mathrm{mL}$ Pyrex glass bulb under vacuum. When the temperature was returned to ambient and the pressure to atmospheric, a vapor volume was collected and directly injected into the dynamic looped reactor. Decane was introduced in liquid form in a 2-L Pyrex vessel set at $44^{\circ} \mathrm{C}$. When equilibrium was reached, a vapor volume was collected and injected into the reactor. The initial concentrations for each compound in the closedloop reactor were set at $800 \mathrm{ppb}$.

\subsection{Closed-loop photocatalytic reactor}

The photocatalytic oxidation experiments were performed in a multi-pass reactor operating in recirculation mode, as presented in 
Fig. 1. Its design has already been described in more detail in previous papers $[20,21]$. Recent papers give a detailed description of the modeling of the reactor [22,23].

In the present work, the reactor included a photocatalytic unit containing a planar geometry photocatalytic filter and four 9-W UVA fluorescent tubes (Philips PL-S series), a centrifugal fan (VSB14-4T, ATIB) and an air tranquillization chamber. The geometry of the photocatalytic unit was designed in order to ensure a homogeneous flow field, photon flux and concentration over the entire photocatalyst surface. The total volume of the reactor was $420 \mathrm{~L}$.

The air stream flowing through the photocatalytic unit was controlled by the fan. For the present study, the flow was set at $28.8 \mathrm{Nm}^{3} \mathrm{~h}^{-1}$ and the relative humidity was set at $50 \%\left(24^{\circ} \mathrm{C}\right)$. The studied compounds were injected and sampled in the air tranquilization chamber. The UV photon flux was mapped over the entire photocatalytic medium surface and the average irradiation intensity was set at $\mathrm{I}_{\text {aver }}=0.5 \pm 0.1 \mathrm{~mW} \mathrm{~cm}^{-2}$ when measured with a Fisher VLX-3W radiometer for the $355-375 \mathrm{~nm}$ UV wavelength range.

Prior to the degradation experiments, leak tests were performed. For instance, leaks were estimated to be lower than $4 \mathrm{ppb}$ per hour for toluene over an observation period of $20 \mathrm{~h}$.

The photocatalytic medium was specifically produced and supplied by Ahlström Paper Group. It was constituted of a $250 \mu \mathrm{m}$-thick fibrous support made of cellulose, polyester and polyamide, coated with a 50/ $50 \mathrm{P} 25 \mathrm{TiO}_{2} / \mathrm{SiO}_{2}$ mixture. Fig. 2 illustrates scanning electron microscopy (SEM) images of the photocatalytic medium. The areal weight of $\mathrm{TiO}_{2}$ deposited on the support was $17 \mathrm{~g} \mathrm{~m}^{-2}$. The medium surface developed by the planar filter was $400 \mathrm{~cm}^{2}$ corresponding to a $\mathrm{TiO}_{2}$ mass of $0.68 \mathrm{~g}$.

\subsection{Sampling and analytical methods}

Different analytical devices were used to characterize the gas phase. The first was an automatic sampling system ACROSS (Automatic Clean Room Sampling System) from TERA-Environnement. The system carries out off-line sampling on multi-sorbent cartridges (Carbopack C + Carbopack B + Carbopack X) and 2,4-dinitrophenylhydrazine (DNPH) cartridges. The former were prepared by Perkin-Elmer for sampling the VOCs present in humid air, the latter were provided by Waters for sampling carbonyl compounds and, more specifically, formaldehyde.

$1 \mathrm{~L}$ was sampled on each Perkin-Elmer multi-sorbent cartridge at a flow rate of $100 \mathrm{~mL} \mathrm{~min}^{-1}$ at $10{ }^{\circ} \mathrm{C}$ (Table 1 ). Then analyses were performed using a Perkin Elmer TD/GC/FID/MS system (Thermal Desorption/Gas Chromatography/Flame Ionization Detector/Mass Spectrometer). This equipment was used to identify and quantify a large range of VOCs and then to quantify the targeted VOCs (toluene, $n$ -
Table 1

Operating parameters for the sampling and TD/GC/FID/MS analysis.

\begin{tabular}{lll}
\hline \multirow{2}{*}{ Sampling parameters } & Temperature $\left({ }^{\circ} \mathrm{C}\right)$ & 10 \\
& Volume $(\mathrm{L})$ & 1 \\
& Flow rate $\left(\mathrm{mL} \mathrm{min}^{-1}\right)$ & 100 \\
TD parameters & Flow rate $\left(\mathrm{mL} \mathrm{min}{ }^{-1}\right)$ & 40 \\
& Final temperature $\left({ }^{\circ} \mathrm{C}\right)$ & 250 \\
Refocusing parameters and injection & Desorption period $(\min )$ & 10 \\
& Initial trap temperature $\left({ }^{\circ} \mathrm{C}\right)$ & -30 \\
& Temperature ramp $\left({ }^{\circ} \mathrm{C} \mathrm{s}{ }^{-1}\right)$ & 40 \\
Chromatographic elution & Final trap temperature $\left({ }^{\circ} \mathrm{C}\right)$ & 250 \\
& Initial temperature $\left({ }^{\circ} \mathrm{C}\right)$ & 0 \\
& Final temperature $\left({ }^{\circ} \mathrm{C}\right)$ & 250 \\
& Flow rate $\left(\mathrm{mL} \mathrm{min}{ }^{-1}\right)$ & 3
\end{tabular}

decane and TCE) and their potential reaction intermediates. The analytical parameters of the methods are summarized in A gas tank, containing 29 standard VOCs in the gas phase, was provided by Praxair. These standard compounds were previously selected because they were identified as being potential intermediates of the selected primary VOCs. Chromatographic separation was optimized using these standards and an appropriate column temperature ramp and elution flow rate were selected. The calibration curves were obtained using the gas tank of standards diluted with VOC-free (using a Claind AZ 2020 airzero generator) and humid air with appropriate mixing ratios using mass flow controllers. The calibration curves were determined using concentrations ranging from $1 \mathrm{ppb}$ to $100 \mathrm{ppb}$ for each compound except toluene, $n$-decane and TCE for which the calibration was determined between $1 \mathrm{ppb}$ and $1000 \mathrm{ppb}$. Retention times, relative response factors, determination coefficients on the calibration curves as well as limits of detection for each compound are given in Table 2 . The limits of detection were determined considering a signal over noise ratio of 3 .

Gas chromatography enables a wide diversity of VOCs to be monitored but this technique is not suitable for formaldehyde. However, this molecule is a key compound for indoor air quality and is expected to be one of the most abundant by-products during photocatalytic VOC oxidation. Thus, formaldehyde was monitored using a derivatization sampling following the US EPA method [24,25] and an HPLC/UV analysis. The same method was also used for acetaldehyde. Calibration curves were carried out using commercial standards of hydrazones of interest. In order to validate this method, complementary points were performed using the gaseous standard for the measurement of acetaldehyde. Then an additional calibration curve was drawn for acetaldehyde. The difference between both calibrations using a liquid or gaseous standard was evaluated as only $6 \%$. Limits of detection obtained for formaldehyde and acetaldehyde as well as the relative response coefficient and the chromatographic retention time are
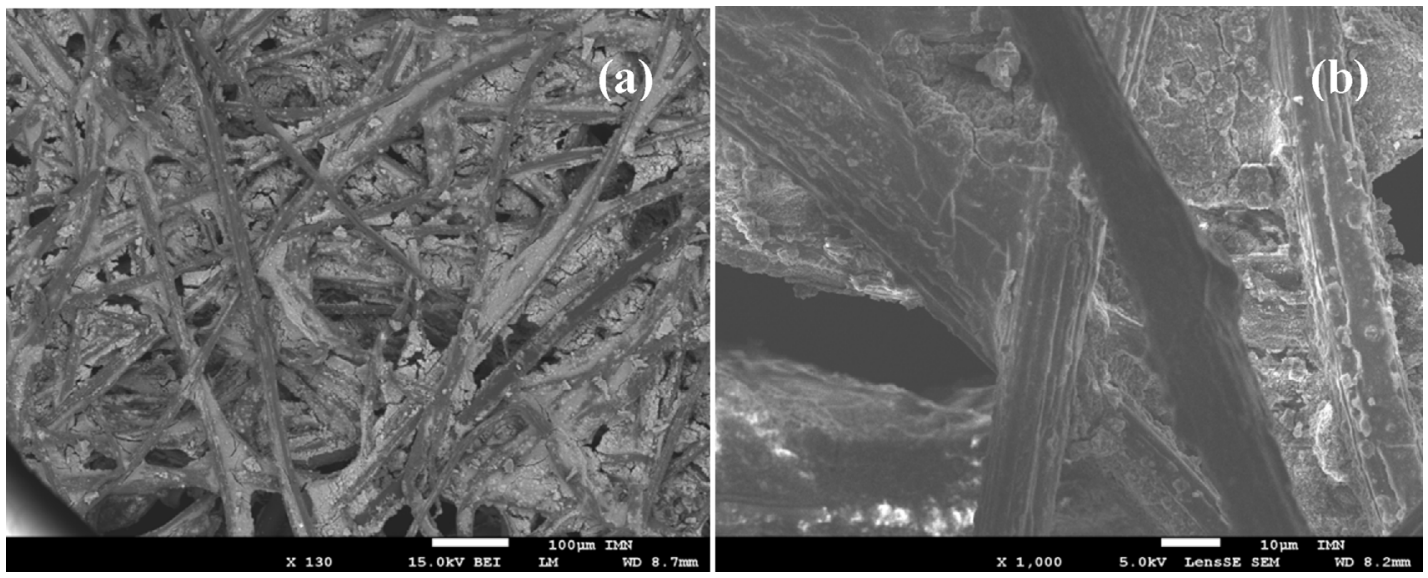

Fig. 2. SEM images of PCO medium - (a) $15.0 \mathrm{kV}$, x 130; (b) $5.0 \mathrm{kV}$, x 1000. 
Table 2

List of the compounds in the standard mixture from Praxair and information on their gas chromatographic analysis and limit of detection $\left(t_{R}:\right.$ chromatographic retention time, $k$ : relative response factor, $\mathrm{R}^{2}$ : determination coefficient on the calibration curve, LOD: limit of detection)

\begin{tabular}{|c|c|c|c|c|c|}
\hline Compound & $\begin{array}{l}\text { Standard } \\
\text { concentration } \\
\text { (ppb) }\end{array}$ & $\mathrm{t}_{\mathrm{R}}(\min )$ & $\mathrm{k}\left(\mathrm{a} u p p b^{-1}\right)$ & $\mathrm{R}^{2}$ & $\begin{array}{l}\text { LOD } \\
\text { (ppt) }\end{array}$ \\
\hline Chloromethane & 1030 & 5.98 & 11 & 0.981 & 8881 \\
\hline Acetaldehyde & 1020 & 7.48 & 213 & 0.934 & 470 \\
\hline Methanol & 1200 & 8.52 & 165 & 0.879 & 604 \\
\hline Methyl formate & 1060 & 9.00 & 415 & 0.966 & 241 \\
\hline Chloroethane & 1040 & 9.29 & 678 & 0.932 & 148 \\
\hline Ethanol & 1150 & 11.75 & 689 & 0.973 & 145 \\
\hline Diethyl ether & 1070 & 11.88 & 2778 & 0.982 & 36 \\
\hline Propanal & 1080 & 12.47 & 1109 & 0.994 & 90 \\
\hline Acetone & 1060 & 12.72 & 1450 & 0.984 & 69 \\
\hline Ethyl formate & 920 & 13.17 & 1303 & 0.973 & 77 \\
\hline Isopropanol & 1060 & 13.35 & 994 & 0.969 & 101 \\
\hline Methyl acetate & 1110 & 13.62 & 1424 & 0.964 & 70 \\
\hline Dichloromethane & 1060 & 13.89 & 636 & 0.954 & 157 \\
\hline Methyl Vinyl Ketone & 1080 & 16.13 & 1653 & 0.989 & 60 \\
\hline Butanal & 1050 & 16.13 & & & \\
\hline 2-butanone & 1040 & 16.41 & 2275 & 0.985 & 44 \\
\hline Ethyl acetate & 1050 & 16.48 & 2078 & 0.991 & 48 \\
\hline Trichloromethane & 1070 & 16.97 & 699 & 0.972 & 143 \\
\hline Tetrachloromethane & 1080 & 17.44 & 731 & 0.983 & 137 \\
\hline Benzene & 1090 & 17.74 & 4352 & 0.973 & 23 \\
\hline Trichloroethylene & 1040 & 18.67 & 1486 & 0.981 & 67 \\
\hline Pentanal & 1030 & 19.0 & 1503 & 0.992 & 67 \\
\hline Toluene & 1050 & 20.52 & 4741 & 0.965 & 21 \\
\hline Hexanal & 1010 & 21.42 & 2278 & 0.965 & 44 \\
\hline Chlorobenzene & 1050 & 22.44 & 3695 & 0.969 & 27 \\
\hline Heptanal & 740 & 23.42 & 1655 & 0.964 & 60 \\
\hline Decane & 1100 & 24.36 & 1998 & 0.907 & 50 \\
\hline Benzaldehyde & 1070 & 25.08 & 1326 & 0.893 & 75 \\
\hline Octanal & 1010 & 25.17 & 801 & 0.920 & 125 \\
\hline
\end{tabular}

Table 3

Calibration of formaldehyde and acetaldehyde using the DNPH/HPLC method and information on their chromatographic analysis and limits of detection $\left(t_{R}\right.$ : chromatographic retention time, $\mathrm{k}$ : relative response factor, $\mathrm{R}^{2}$ : determination coefficient on the calibration curve, LOD: limit of detection).

\begin{tabular}{llllll}
\hline Compound & Standard phase & $\mathrm{t}_{\mathrm{R}}(\min )$ & $\mathrm{k}\left(\mathrm{a} \cdot \mathrm{u} \cdot \mathrm{ppb}^{-1}\right)$ & $\mathrm{R}^{2}$ & $\mathrm{LOD}(\mathrm{ppb})$ \\
\hline Formaldehyde & liquid & 3.1 & 1530 & 0.9981 & 1 \\
Acetaldehyde & liquid & 3.9 & 1486 & 0.9990 & 1 \\
& gas & & 1395 & 0.9957 & \\
\hline
\end{tabular}

presented in Table 3 .

\section{Results and discussion}

\subsection{Degradation rates and reaction intermediate formation for individual} VOCs

\subsubsection{Toluene, $n$-decane and TCE individual degradations}

This research deals with the study of the photocatalytic oxidation of a mixture of toluene, $n$-decane and TCE in a recirculation closed-loop reactor. It is essential to assess first the single-component PCO kinetics separately. Each degradation was repeated twice for the evaluation of the experimental deviation. Fig. 3 displays one of the PCO kinetic curves for toluene, $n$-decane and TCE as single contaminants.

It can be seen in Fig. 3 that the complete degradation of $n$-decane and toluene was achieved within 2 and $3 \mathrm{~h}$, respectively. The photodegradation of TCE was performed in experimental conditions similar to toluene and $n$-decane photooxidation experiments. However, the initial TCE concentration was slightly lower due to the variability in the generation of polluted air. In contrast with toluene and $n$-decane, the degradation of TCE was very slow. In fact, beyond $16 \mathrm{~h}$ of reaction, the complete oxidation of TCE was still not achieved and $90 \mathrm{ppb}$ of TCE still remained in the gas phase.

Two hypotheses can be proposed to explain the relatively low reaction rate for TCE degradation.

First, TCE behavior can be related to its sorption capacity onto the photocatalytic medium. The low reaction rate for TCE degradation may be attributed to the relative humidity (RH) effect. Indeed, Petit et al. [26], Hedegus and Dombi [27] and Ou and Lo [28] have shown that water molecules trigger an inhibitory effect on TCE degradation. The presence of water molecules in the gas phase leads to a hydroxylated titania surface that decreases opportunities for TCE to adsorb on the active sites. Water molecules might compete with TCE molecules on the photocatalyst surface sites during adsorption [11]. In our former work, it was shown that the degradation of TCE significantly decreases because of competitive adsorption occurring between the VOCs present in the mixture [9]. This point is further discussed in section 3.2.1.

Second, the lowest degradation rate for TCE can be attributed to the contact time between the molecules and the photocatalytic material. It was shown in our former work, performed in the 120-L Pyrex batch reactor, that TCE can be degraded faster than toluene and $n$-decane for experiments also conducted at ppb level [9]. The main difference with this present work is that in the closed-loop reactor, the contact time, related to the air flow rate through the photocatalytic medium, is an influencing parameter [29]. TCE is the most volatile compound compared to toluene and $n$-decane, and its degradation can be significantly decreased by the modification of the dynamic regime. Further experiments are needed to investigate this but it is supposed that the air flow rate to the medium has a significant influence on TCE degradation. In fact, to promote the industrial implementation of PCO systems better, optimization and intensification seem necessary for the removal of this kind of molecule [30].

In order to compare the degradation of the three VOCs quantitatively, simple indicators were researched. It can be observed that the photocatalytic degradation of toluene and $n$-decane follows an almost mono-exponential decay during the whole irradiation time:

$\mathrm{C}=\mathrm{C}_{0} \exp \left(-\mathrm{k}_{\mathrm{app}} \mathrm{t}\right)$

By plotting the logarithm of the concentration versus time for toluene and $n$-decane, an apparent first-order decay constant $k_{\text {app }}$ can be calculated.

Fig. 4 shows examples of the calculation of $k_{\text {app }}$ for the degradation of toluene and $n$-decane as single components. This constant could also be calculated for the degradation of TCE; however the decay does not follow an entirely mono-exponential behavior. This means that the decay constant should be calculated on the mono-exponential part only, taking into account fewer points and leading to higher uncertainty. For this reason, the time constant of the degradation is used as a more relevant indicator since it can be calculated irrespective of the degradation kinetics. The time constant, $t_{c}$, is the time for which the efficiency of degradation $\mathrm{E}$ reaches $63.2 \%$, with:

$\mathrm{E}=\frac{\mathrm{C}_{0}-\mathrm{C}}{\mathrm{C}_{0}}$

In other words, the time constant corresponds to $\mathrm{C} / \mathrm{C}_{0}=36.8 \%$. It is directly determined from the degradation curves.

Then, the apparent first-order kinetic constant $\mathrm{k}_{\mathrm{app}}$ as well as the time constant $t_{c}$ can be used to make comparisons between experimental results.

Table 4 displays the values of the apparent first-order kinetic and time constants for the three studied VOCs as single components. Experimental deviation is also given.

\subsubsection{Reaction intermediate formation during toluene degradation}

In the present work, five reaction intermediates were detected in the gas phase during the photocatalytic degradation of toluene under 

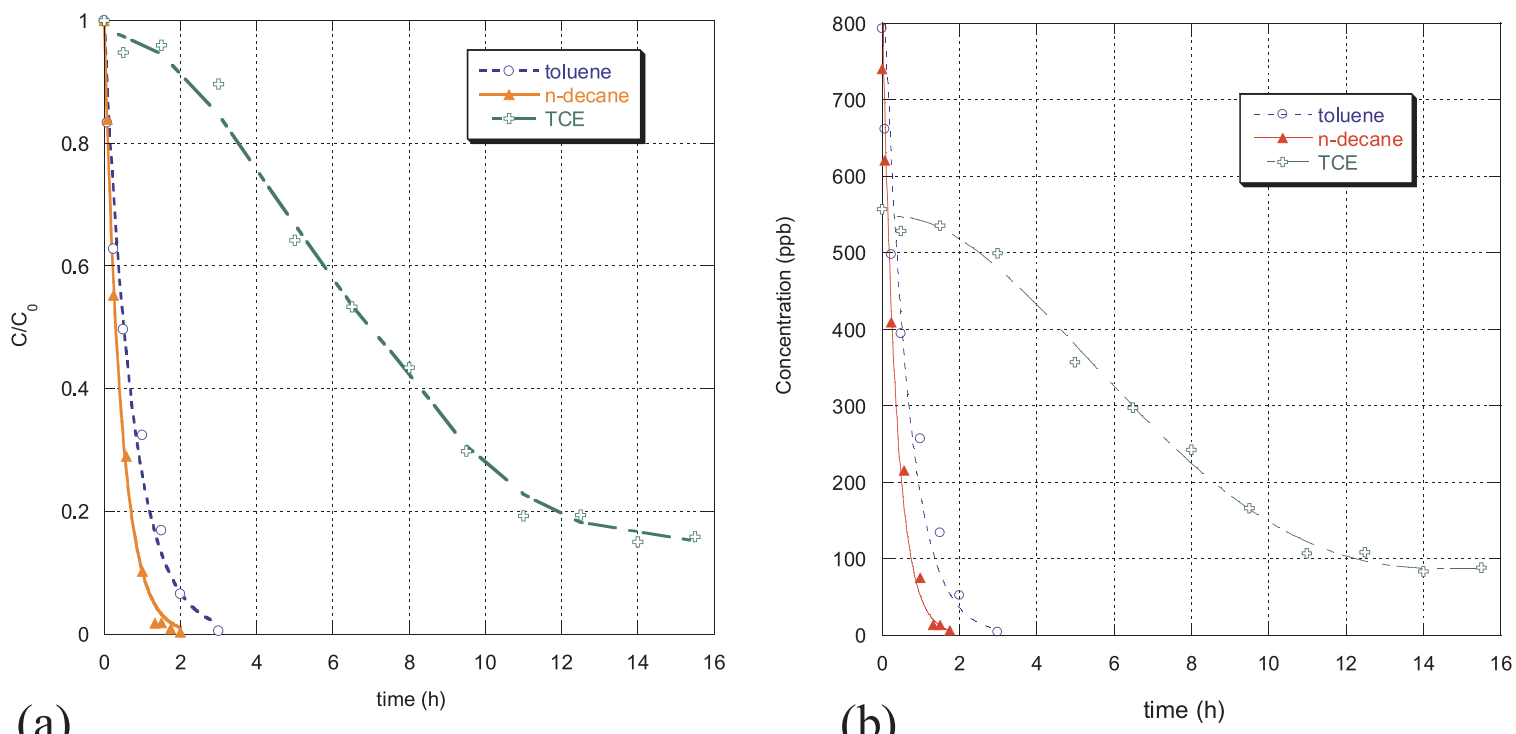

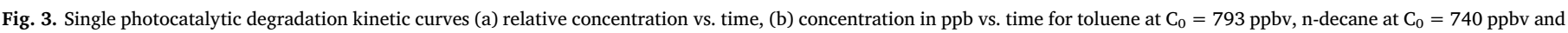
TCE at $\mathrm{C}_{0}=557$ ppbv.

humid conditions $\left(\left[\mathrm{H}_{2} \mathrm{O}\right]=13,000 \mathrm{ppmv}\right)$ : formaldehyde, acetaldehyde, benzaldehyde, benzene and methanol. The concentrations of these compounds were measured in the gas phase throughout the experiment (Fig. 5). For every compound, the concentration increased, reached a maximum and then decreased until the almost total removal of the intermediates. The concentrations of benzene and benzaldehyde immediately increased after the beginning of the experiment, revealing that they are primary intermediates whereas the concentration increase for methanol, formaldehyde and acetaldehyde was approximately $15 \mathrm{~min}$ later. These three compounds are secondary intermediates in the toluene photocatalytic degradation pathway. The maximum concentrations for the five intermediates were reached beyond one hour of irradiation. The maximum values were $0.08 \mathrm{ppb}$ for benzene, $3.7 \mathrm{ppb}$ for benzaldehyde, $5 \mathrm{ppb}$ for methanol and acetaldehyde and ca. $23 \mathrm{ppb}$ for formaldehyde. These results are in accordance with the literature [6,31].

These results are also in accordance with the previous study carried out in a batch reactor and presented in Debono et al. [14] in which 16 intermediates were detected in the gas phase during the photocatalytic degradation of toluene in a humid atmosphere $(\mathrm{RH}=50 \%)$ and with an
Table 4

Mean apparent first-order kinetic constants $k_{a p p}$ and time constant of degradation $t_{c}$ for toluene, $\mathrm{n}$-decane and TCE when they are degraded as single components.

\begin{tabular}{lll}
\hline & $\mathrm{k}_{\text {app }}$ single-component exp. $\left(\mathrm{h}^{-1}\right)$ & $\mathrm{t}_{\mathrm{c}}$ single-component exp. (h) \\
\hline Toluene & $1.19 \pm 0.13$ & $0.85 \pm 0.05$ \\
$n$-decane & $2.24 \pm 0.10$ & $0.52 \pm 0.03$ \\
TCE & Not determined & $7.74 \pm 0.90$ \\
\hline
\end{tabular}

initial concentration of $800 \mathrm{ppb}$. Only 5 intermediates were identified in this study compared to the previous one, probably due to the more rapid degradation of toluene. In our previous study, the main reaction pathway of the toluene PCO was well described, resulting in primary intermediates (benzaldehyde and o-, m-, p-cresols, for instance) followed by secondary intermediates due to the aromatic ring-opening. In fact, aldehydes are the major compounds in terms of diversity and concentration, highlighting the importance of monitoring the smaller aldehyde molecules: acetaldehyde and formaldehyde. These give a good evaluation of the progress of the oxidizing process.
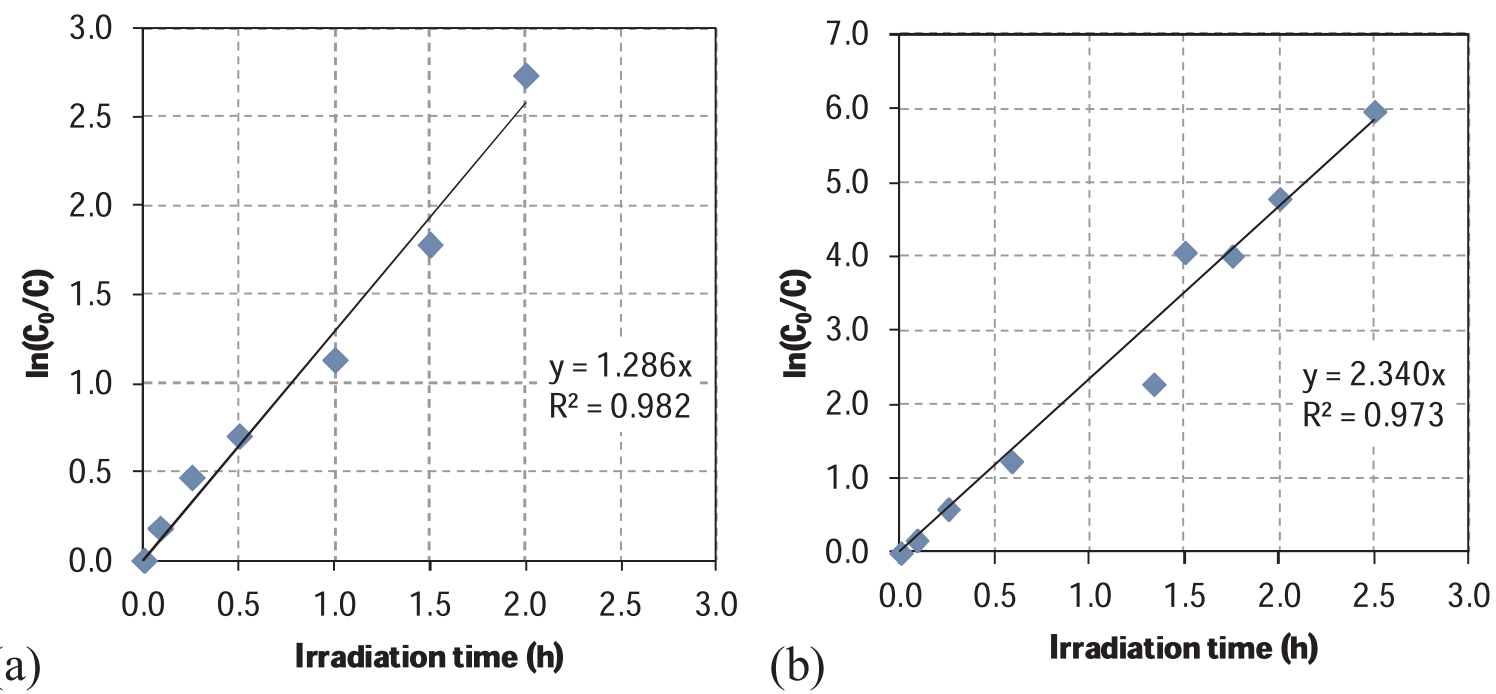

Fig. 4. Determination of $k_{a p p}$ for the photocatalytic degradation of (a) toluene, (b) n-decane. 

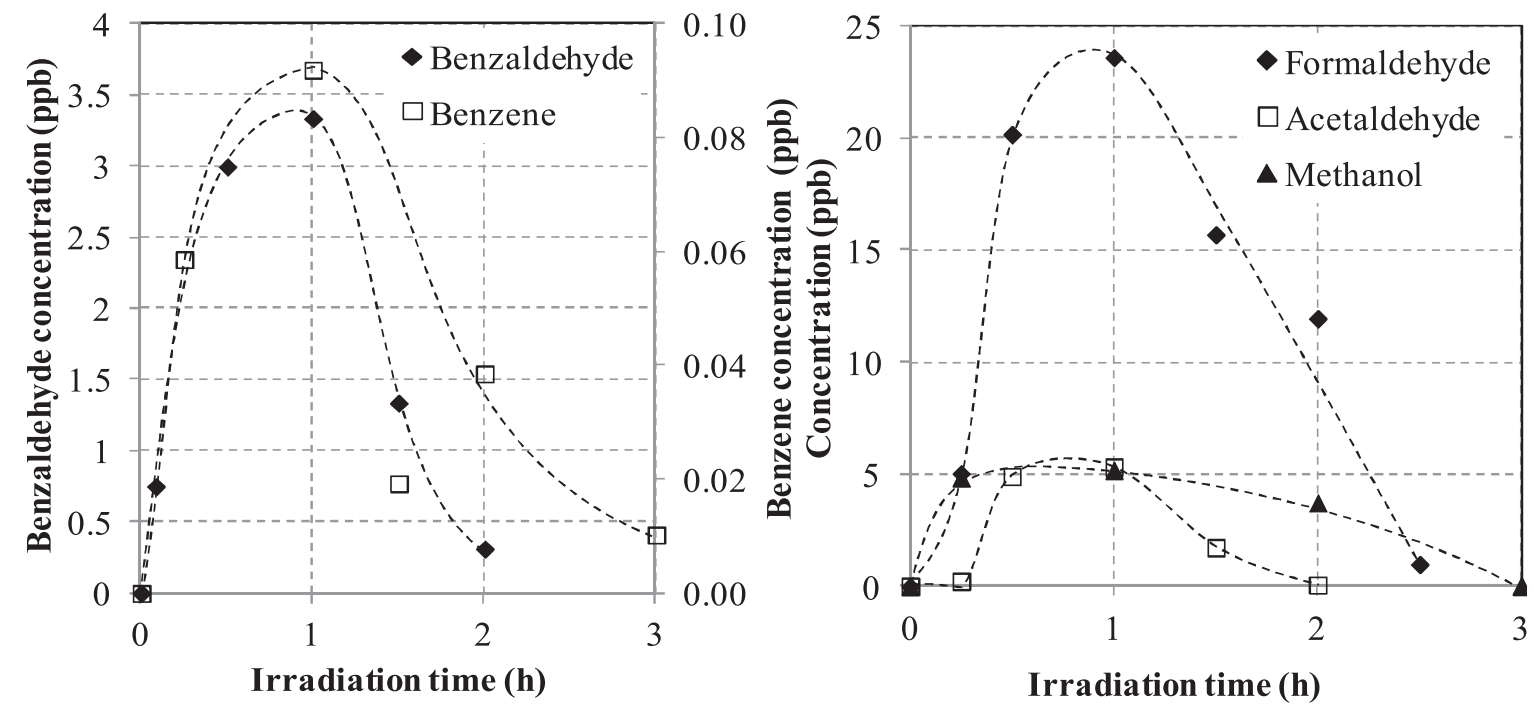

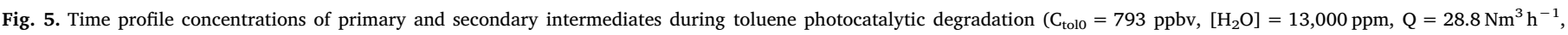
$\mathrm{I}=0.5 \mathrm{~mW} \mathrm{~cm}^{-2}$ ).

\subsubsection{Reaction intermediate formation during $n$-decane degradation}

Ten reaction intermediates were detected in the gas phase during the photocatalytic degradation of $n$-decane under humid conditions $\left(\left[\mathrm{H}_{2} \mathrm{O}\right]=13,000\right.$ ppmv $)$. Their classification is presented in Table 5. A three-step profile was again identified through the kinetic curve; intermediate formation, maximum concentration, and then degradation until the almost total removal of the intermediates (Fig. 6).

These results are in accordance with the literature in which the main identified intermediates are aldehydes and ketones [32]. They are also in accordance with the reaction intermediates identified in the previous study by Debono et al. [14], following the highlighted reaction pathway. However, the intermediate degradations were much more rapid, about ten times faster; the maximum concentrations were reached in about $10 \mathrm{~h}$ in Debono et al., instead of about $1 \mathrm{~h}$ in the present study and only 10 intermediates were found instead of 18 . In the present study, the closed loop-reactor avoided mass transfer limitation and allowed sufficient contact time between the pollutants and the photocatalytic material. The quantity of titanium dioxide involved in this case corresponded to $680 \mathrm{mg}$ instead of $100 \mathrm{mg}$ P25-Degussa $\mathrm{TiO}_{2}$ powder in Debono et al. Again, there were numerous aldehydes and it can be noted that acetaldehyde and formaldehyde were the last produced intermediates with the highest concentrations. These molecules indicate the progress of the oxidation process.

\subsubsection{Reaction intermediate formation during TCE degradation}

In Fig. 7(a) where two degradations of single TCE are represented (one with $\mathrm{C}_{0}=557 \mathrm{ppbv}$ and the other with $\mathrm{C}_{0}=493 \mathrm{ppbv}$ ), a threestep degradation mechanism can be observed, as mentioned in section 3.1.1, with a first region where TCE degradation was slow, a region where the conversion rate increased significantly and a third region where the TCE removal seemed to be stopped as the concentration reached a plateau. In Fig. 7(b), the TCE degradation rate profile is

Table 5

List of the reaction intermediates identified in the gas phase during photocatalytic degradation of $\mathrm{n}$-decane $\left(\mathrm{C}_{0}=740 \mathrm{ppb},\left[\mathrm{H}_{2} \mathrm{O}\right]=13,000 \mathrm{ppm}\right)$.

\begin{tabular}{llll}
\hline Aldehydes & Ketones & Alcohols & Others \\
\hline Formaldehyde & Acetone & Ethanol & $\begin{array}{l}\text { Methyl acetate } \\
\text { Ecetaldehyde }\end{array}$ \\
$\begin{array}{l}\text { Propanal } \\
\text { Butanal }\end{array}$ & & \\
Pentanal & & \\
\hline
\end{tabular}

represented. The degradation rates rose to 54 and $68 \mathrm{ppbh}^{-1}$ within $5 \mathrm{~h}$ and then decreased, highlighting the three steps in the TCE degradation mechanism. It is commonly agreed in the literature that trichloroethylene undergoes a chain reaction mechanism involving both $\mathrm{OH} \cdot$ and $\mathrm{Cl} \cdot$ radicals $[33,28,18]$. The first region could correspond to hydroxyl radical reactions with TCE. These are designated as initiation reactions and are thought to release chlorine radicals that further react with TCE and enhance conversion rates. The second region could be attributed to the reactions of TCE with $\mathrm{Cl} \cdot$, which are the predominant oxidant species in this case. Some reaction intermediates such as dichloroacetaldehyde chloride (DCAC) and phosgene have been detected in the gas phase during the photocatalytic degradation of TCE [34-36] and may compete with TCE regarding adsorption on the $\mathrm{TiO}_{2}$ medium and/or a competitive degradation reaction. The formation of these reaction intermediates can interfere with TCE adsorption and degradation and may explain the trend of the TCE PCO kinetic curve after $10 \mathrm{~h}$ of experiment. Joung et al. observed that the sole adsorbed species on $\mathrm{TiO}_{2}$ during TCE photocatalytic degradation, using silica wafers coated with titanium dioxide as photocatalyst, was adsorbed DCAC. Adsorbed DCAC on $\mathrm{TiO}_{2}$ formed carboxylate compounds reducing the rate of TCE photocatalytic oxidation.

Fig. 8 presents the 5 intermediates that were detected during TCE degradation for $15 \mathrm{~h}$ : dichloromethane, acetone, diethyl ether, ethanol and acetaldehyde. No other chlorinated compounds were detected in this study because they were probably formed at lower concentrations than the limit of detection of the analytical methods. Several oxygenated compounds were formed and degraded. They may result from a specific pathway already described by Wang et al. [37]. According to Eq. (3), Wang et al. proposed that chlorinated compounds are hydrolyzed into alcohol. The latter are then transformed into aldehyde and acids until complete mineralization. As a result, TCE can be a source of chlorinated compounds as well as oxygenated compounds.

Based on the literature information and the intermediates detected in these experiments, it seems that the reaction mechanism for heterogeneous photocatalytic oxidation of TCE may involve a series of reactions with initial dechlorination. The major pathways probably lead to the formation of dichloroacetyl chloride and phosgene, not detected here, along with small portions of chlorination to form chloroalkanes, like dichloromethane. The chloroalkanes are then further transformed into alcohols, aldehydes and other oxygenated compounds.

$\mathrm{RCl}+\mathrm{HO}^{-} \rightarrow \mathrm{ROH}+\mathrm{Cl}^{-}$

Eq. (3): Reaction leading to the formation of alcohols from chlorinated 

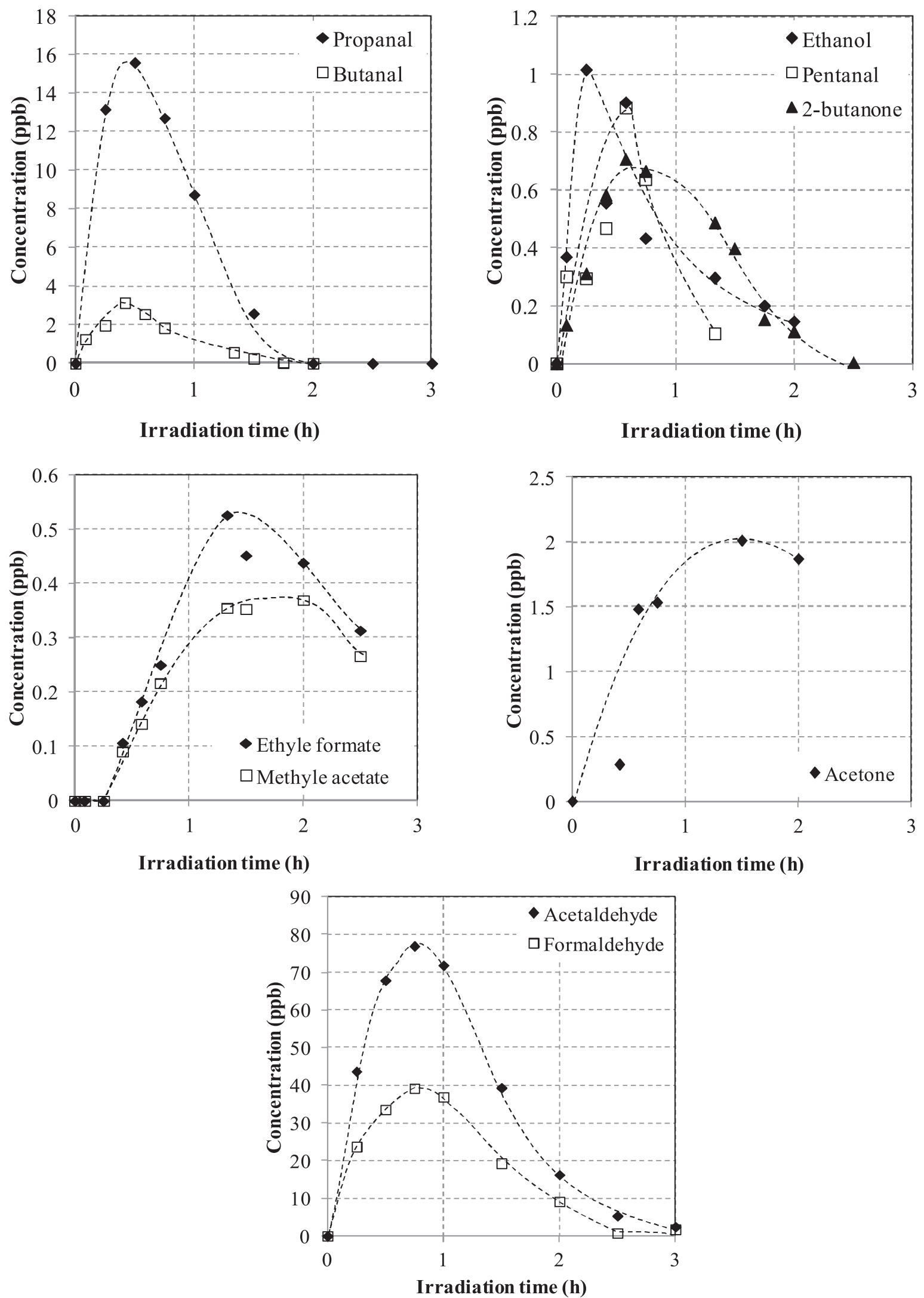

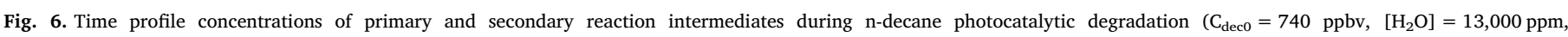
$\mathrm{Q}=28.8 \mathrm{Nm}^{3} \mathrm{~h}^{-1}, \mathrm{I}=0.5 \mathrm{~mW} \mathrm{~cm}^{-2}$ ). 

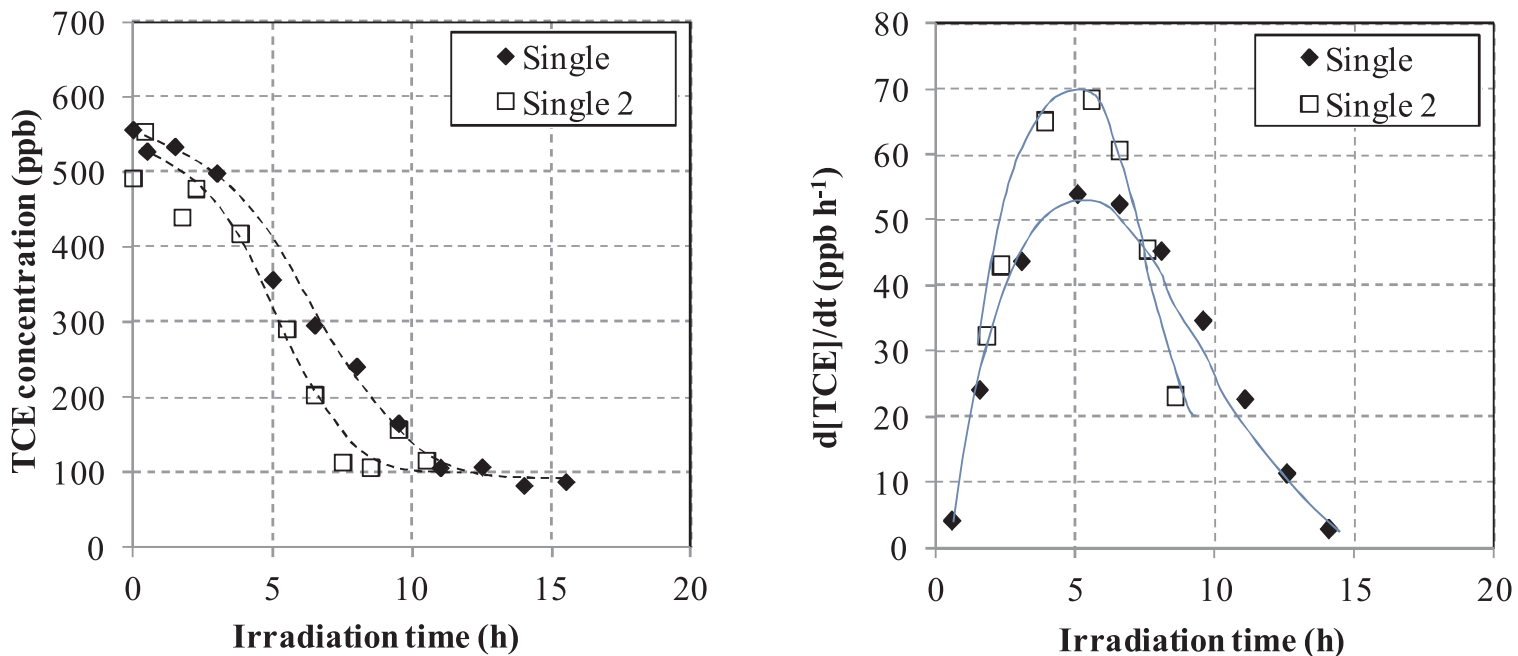

Fig. 7. Photocatalytic degradation of TCE only with $\mathrm{C}_{0}=557 \mathrm{ppbv}$ and $\mathrm{C}_{0}=493 \mathrm{ppbv}$, (a) time profile concentration, (b) time evolution of TCE degradation rate d[TCE]/dt.
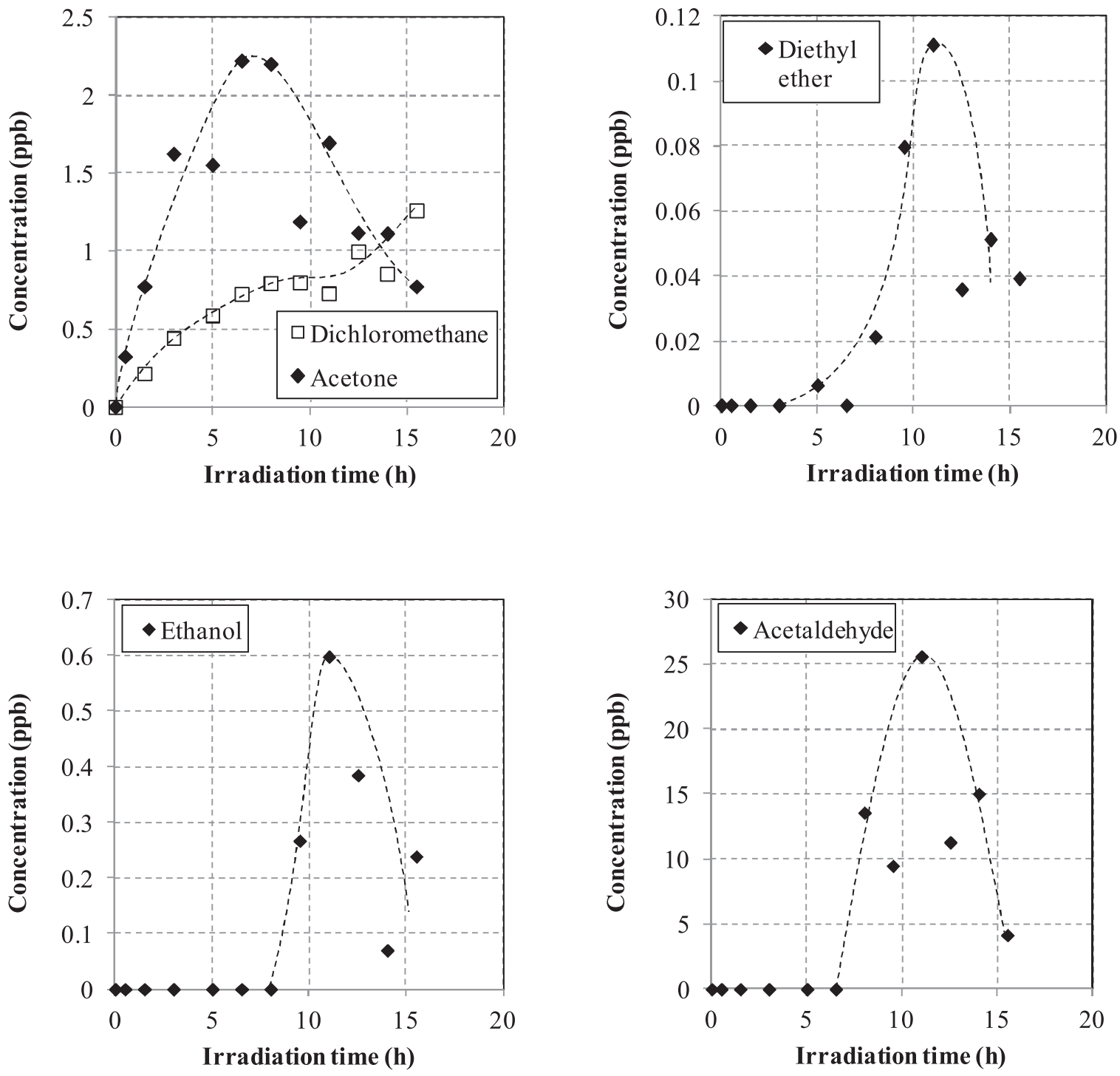

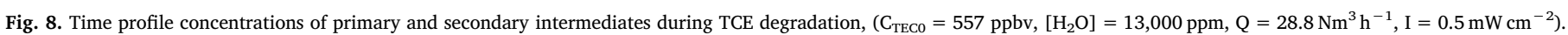




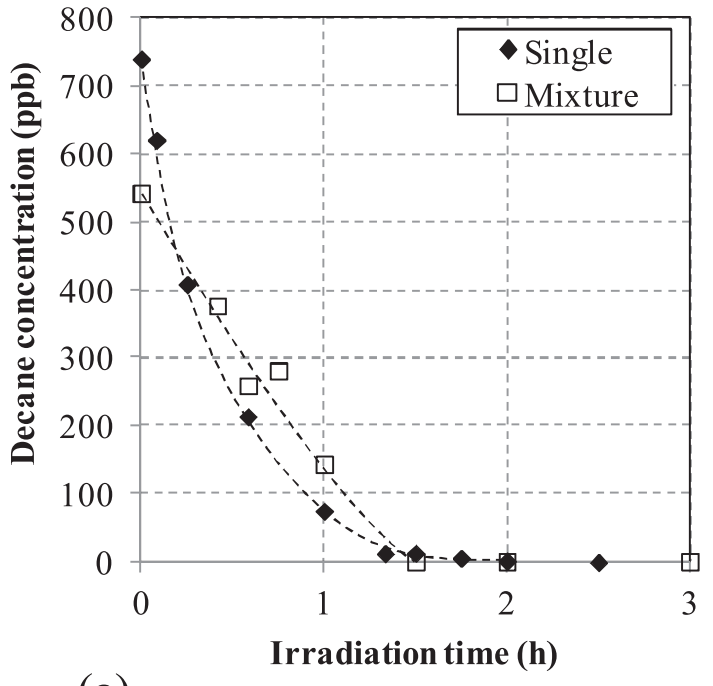

(a)

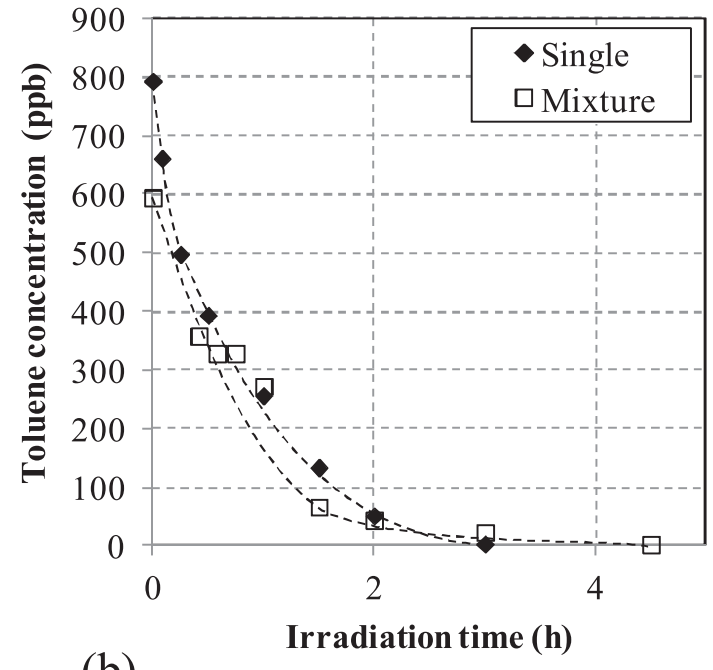

(b)

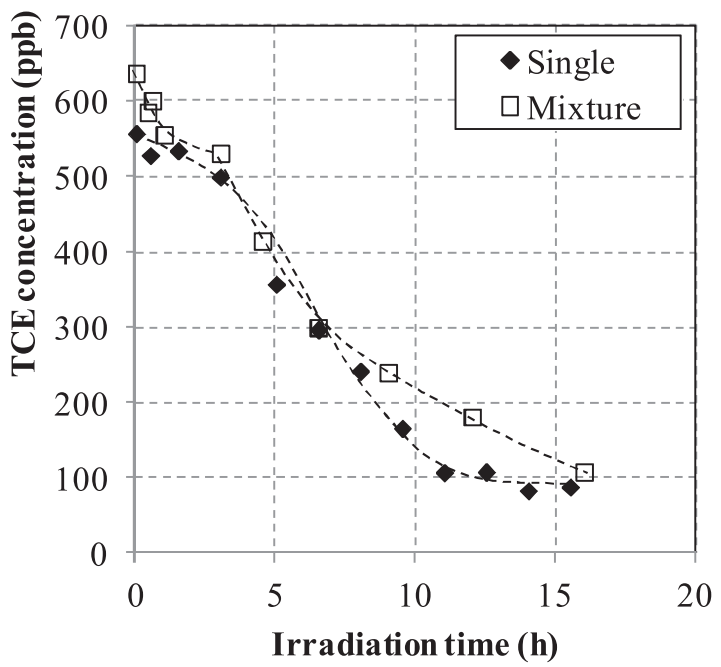

(c)

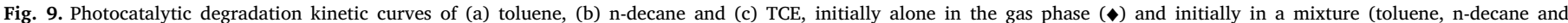
trichloroethylene) $(\square),\left(\mathrm{C}_{0}=543-793 \mathrm{ppbv},\left[\mathrm{H}_{2} \mathrm{O}\right]=13,000 \mathrm{ppm}, \mathrm{Q}=28.8 \mathrm{Nm}^{3} \mathrm{~h}^{-1}, \mathrm{I}=0.5 \mathrm{~mW} \mathrm{~cm}^{-2}\right)$.

Table 6

Apparent first-order kinetic constants $\mathrm{k}_{\mathrm{app}}$ and time constant of degradation $\mathrm{t}_{\mathrm{c}}$ for toluene, $\mathrm{n}$-decane and TCE (h) when they are in a mixture.

\begin{tabular}{lll}
\hline & $\mathrm{k}_{\text {app }}$ mixture exp. $\left(\mathrm{h}^{-1}\right)$ & $\mathrm{t}_{\mathrm{c}}$ mixture exp. $(\mathrm{h})$ \\
\hline Toluene & $1.03 \pm 0.08$ & $1.35 \pm 0.33$ \\
$n$-decane & $1.88 \pm 0.26$ & $0.62 \pm 0.20$ \\
TCE & Not determined & $9.32 \pm 0.04$ \\
\hline
\end{tabular}

intermediates during TCE PCO [37]

\subsection{Degradation rates and reaction intermediate formation for the mixture of VOCs}

\subsubsection{Comparison of VOC mixture degradation kinetics}

Most gas-solid photocatalytic oxidations discussed in the literature were exclusively limited to single-component pollutant systems; these provide convenient cases for understanding the kinetics of photocatalytic oxidation. For commercial photocatalytic applications, a contaminated air stream often contains more than one contaminant. Therefore, multicomponent system studies are needed to understand photocatalytic oxidation under more realistic process conditions and ultimately provide a stronger photoreactor design basis. The composition of the indoor gas phase is very complex. It contains many different VOCs with quite different characteristics. Therefore, it is necessary to understand the potential interaction mechanisms of pollutants during the photocatalytic process. The degradation rates of the three studied molecules mixed together were thus assessed and compared with single-component experiments. The experimental results are presented in Fig. 9.

Experiments using a mixture were also carried out twice. Apparent kinetic constants $\mathrm{k}_{\mathrm{app}}$ and time constants $\mathrm{t}_{\mathrm{c}}$ were calculated according to the experimental procedure described above. Values are reported in Table 6 . As for degradation of the single component, the kinetic constant of TCE degradation was not determined. To compare TCE degradation, the degradation rate profile was plotted, Fig. 10, for both experiments as a single compound and in a mixture.

The results are consistent with the studies of Destaillats et al. [4] and Hodgson et al. [38] in which several mixtures of VOCs were investigated. A general trend was that the oxidation rates of VOC mixtures followed the approximate order: alcohols and glycol ethers $>$ ( higher than) aldehydes, ketones and terpene hydrocarbons $>$ aromatic 


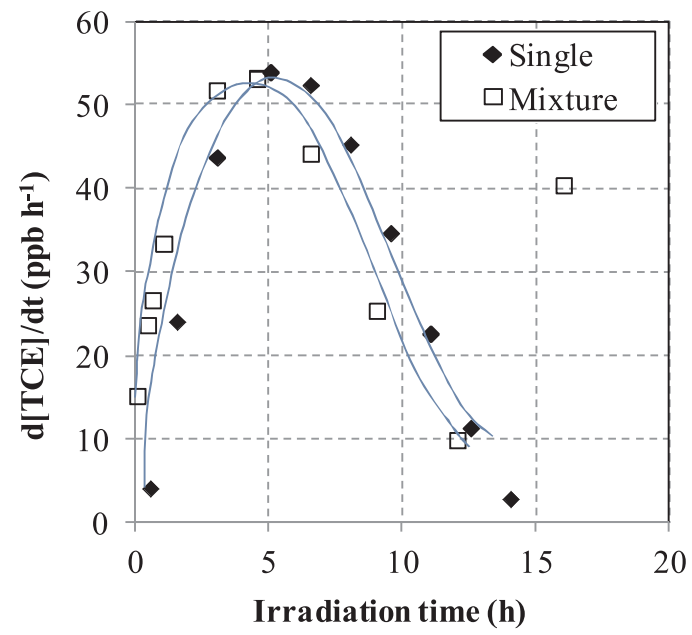

Fig. 10. Evolution of the TCE photocatalytic degradation rate, initially alone in the gas phase $(\diamond)$ and initially in a mixture (toluene, n-decane and trichloroethylene) $(\square)$, $\left(\mathrm{C}_{0}=543-793 \mathrm{ppbv},\left[\mathrm{H}_{2} \mathrm{O}\right]=13,000 \mathrm{ppm}, \mathrm{Q}=28.8 \mathrm{Nm}^{3} \mathrm{~h}^{-1}, \mathrm{I}=0.5 \mathrm{~mW} \mathrm{~cm}^{-2}\right)$.

and alkane hydrocarbons $>$ halogenated aliphatic hydrocarbons. The results presented here show that toluene and $n$-decane were degraded at approximately the same rate in contrast with TCE which was degraded more slowly. In our previous study, presented in Debono et al. [9], the degradation of TCE in a mixture was also slower than for the other two compounds.

Regarding the possible interference when compounds are in a mixture during PCO degradation, a slight difference in the kinetic constants was observed when they were in a mixture compared to single-component degradation. The kinetic constants slowed down slightly but the difference was close to the experimental error. The difference was more noticeable for toluene and decane degradation. The kinetic rates when they were alone or in a mixture were respectively $1.03 \pm 0.08 \mathrm{~h}^{-1}$ instead of $1.19 \pm 0.13 \mathrm{~h}^{-1}$ for toluene, and $1.88 \pm 0.26 \mathrm{~h}^{-1}$ instead of $2.24 \pm 0.10 \mathrm{~h}^{-1}$ for $n$-decane. The time constants slightly increased in a mixture up to $1.35 \pm 0.33 \mathrm{~h}$ instead of $0.85 \pm 0.05 \mathrm{~h}$ for toluene and $0.62 \pm 0.20 \mathrm{~h}$ instead of $0.52 \pm 0.03 \mathrm{~h}$ for decane. These two compounds were degraded in the same time and a possible competition for adsorption on the active sites is possible. Chen and Zhang, [39] observed no significant effect of the mixture regarding the degradation rate of toluene or decane at low concentrations (206 and $170 \mathrm{ppb}$ ) when they were mixed with 2 or 3 compounds from the same chemical families. They noticed a decrease in the conversion rate when the mixture reached 16 compounds and assumed a possible adsorption competition. This conclusion was also made in Debono et al. [9] where it was shown that the photocatalytic removal kinetics of decane and toluene decreased when they were in a mixture in relation to the total initial concentration of VOCs loaded in the reactor.

Regarding TCE, the difference in photocatalytic removal when it was in a mixture or alone was very small. The time constant increased slightly from $7.74 \pm 0.90 \mathrm{~h}$ to $9.32 \pm 0.04 \mathrm{~h}$ and, as seen in Fig. 10, the maximum reaction rate and the time corresponding to it was about $5 \mathrm{~h}$, meaning that there was no significant difference. It was demonstrated in our previous paper, Debono et al. [9], that TCE removal kinetics were impacted when there was a possible competitive adsorption phenomenon or if the surface accessibility was inhibited. In the current work, the air flow rate was not favorable for a rapid degradation of TCE, which occurred after the degradation of toluene and $n$-decane. Thus, the two main hypotheses of interactions, namely; i) a possible competitive adsorption between the ternary mixture leading to a decrease in TCE degradation as TCE is the most volatile compound and ii) a possible consumption of a fraction of the generated reactive chlorinated radicals by toluene and $n$-decane, did not occur. This last point is further discussed below in relation to the possible chlorinated by-products.

3.2.2. Comparison of reaction intermediates from VOC mixture degradation

It has been demonstrated in the literature that the PCO degradation of TCE leads to chlorinated radicals that may react with toluene or decane $[11,40]$. These authors called the rate promotion caused by trichloroethylene a "chlorine promotion" effect, which provides $\mathrm{Cl}^{\circ}$ radical to initiate some possible oxidation chain reactions of other compounds. This may explain the increased toluene degradation rate when it is in a mixture with TCE. The conversion of the latter decreases as toluene has a "quenching effect". However, these observations were made at ppm levels of concentration. It is supposed that at ppb levels, there are few interactions between the three molecules. In fact, it was demonstrated in Debono et al. that few interactions may occur between the different initial compounds leading to specific VOCs originating from reaction intermediate cross-reactivity. It was also shown that at this level of concentration when the degradation of toluene, $n$-decane and TCE occurs at the same time, if there are some interactions between reaction intermediates, this pathway is a minor one. The chlorinated cross-reactivity by-products remain among the intermediates with the lowest concentrations.

As for the present experiments in the closed loop-reactor operating in recirculation mode, this point can be highlighted by looking at the possible formed chlorine compounds. Fourteen intermediate compounds were detected and quantified during the degradation of the three VOCs in a mixture. They are reported in Table 7.

All these compounds were identified during the individual degradation of the three model VOCs. There was no additional identified intermediate when the degradation occurred in a mixture. As already assumed from the degradation rates, there was no significant interaction between the 3 VOCs. Even in a mixture, these molecules were at ppb levels of concentration and little competitive adsorption took place. The degradations of toluene and decane occurred before TCE degradation, resulting in the fact that intermediates did not seem to interfere in the main pathways. Considering the results reported in Fig. 11, it is suggested that the main mechanism paths are similar in multi-compound and single compound experiments.

However, the formation and degradation of the secondary intermediates, and especially acetaldehyde and formaldehyde, took more time when the experiment was carried out in a mixture. It should be noted that the total initial concentration of the three molecules was approximately 3 times higher $\left(\mathrm{C}_{\text {ototal }}=1228\right.$ or $\left.1774 \mathrm{ppb}\right)$. This may have led to an accumulation of intermediates and to an overall slowdown in the degradation of the last intermediates. This observation is in accordance with the conclusions of Debono et al., assuming the effect of the total initial concentration of VOCs on individual degradation rates.

Fig. 12 compares methanol and aldehyde time profiles of concentrations when monitored in a mixture or as single compounds. Looking at the formation and degradation of acetaldehyde and formaldehyde, these final intermediates present the most significant slowdown. However, the maximum concentration of these compounds did not increase that much, even with a three-fold higher total initial concentration for experiments in a mixture; the quantity of the formed

Table 7

List of the reaction intermediates identified in the gas phase during photocatalytic degradation of toluene, $\mathrm{n}$-decane and TCE in a mixture $\left(\mathrm{C}_{0}=543-793 \mathrm{ppb}\right.$, $\left[\mathrm{H}_{2} \mathrm{O}\right]=13,000 \mathrm{ppm}, \mathrm{Q}=28.8 \mathrm{Nm}^{3} \mathrm{~h}^{-1}, \mathrm{I}=0.5 \mathrm{~mW} \mathrm{~cm}^{-2}$ ).

\begin{tabular}{lllll}
\hline Aldehydes & Ketones & Alcohols & Esters & Others \\
\hline Formaldehyde & Acetone & Methanol & Methyl acetate & Benzaldehyde \\
Acetaldehyde & 2-butanone & Ethanol & Ethyl formate & $\begin{array}{l}\text { Dichloromethane } \\
\text { Propanal }\end{array}$ \\
$\begin{array}{l}\text { Butanal } \\
\text { Pentanal }\end{array}$ & & & & \\
\hline
\end{tabular}



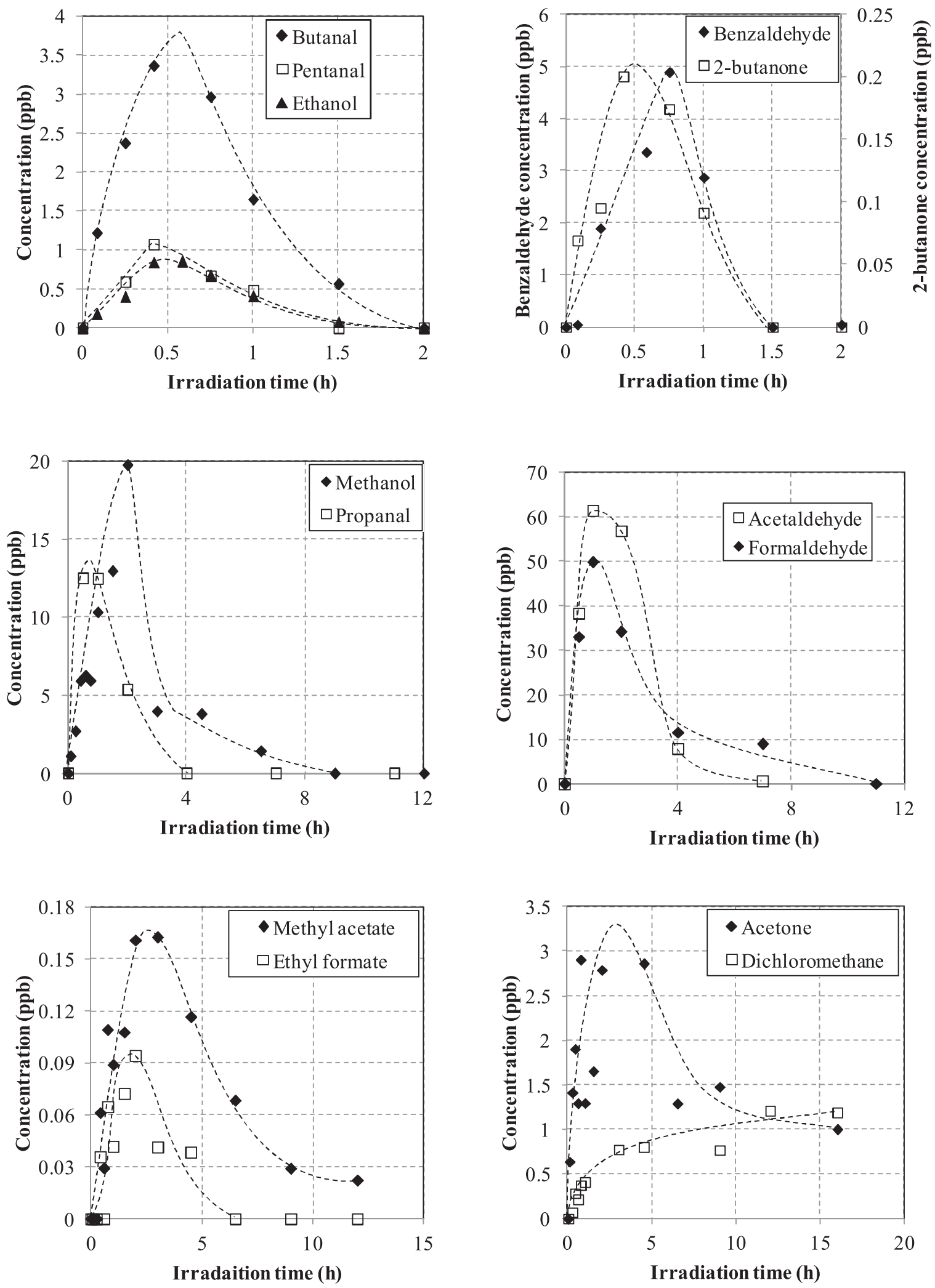

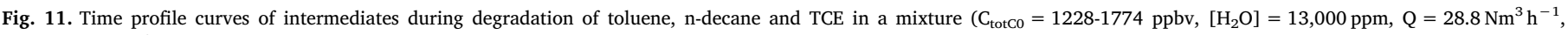
$\mathrm{I}=0.5 \mathrm{~mW} \mathrm{~cm}^{-2}$ ).

intermediates was displayed over a longer period.

As a major conclusion of this section, it can be said that using a dynamic closed-loop reactor and relatively low concentration levels, there is no significant interaction between the degradation mechanisms of each VOC. The main point is that the last formed intermediates may be delayed and their degradation occurs later because of the higher overall concentrations of VOCs. In fact, to evaluate the performance of any PCO system well, it is necessary to monitor the latest formed oxygenated intermediates, which are acetaldehyde and formaldehyde. They represent good indicators of the progress of the oxidation process. 

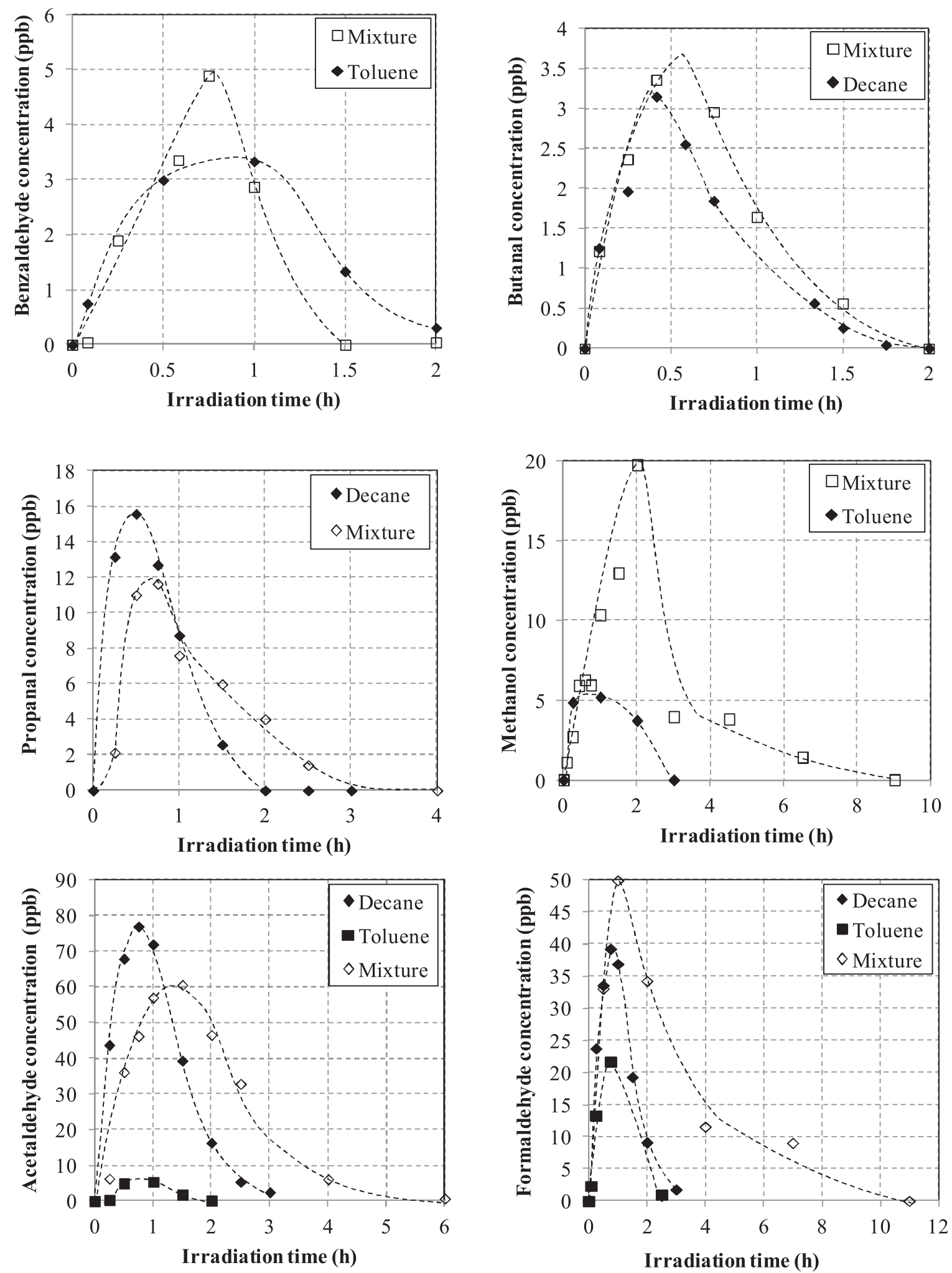

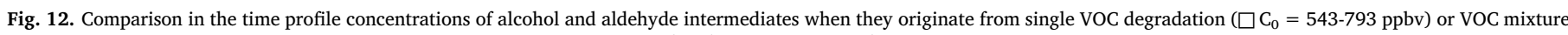
degradation $\left(\diamond \mathrm{C}_{\mathrm{totC0}}=1228-1774 \mathrm{ppbv},\left[\mathrm{H}_{2} \mathrm{O}\right]=13,000 \mathrm{ppm}, \mathrm{Q}=28.8 \mathrm{Nm}^{3} \mathrm{~h}^{-1}, \mathrm{I}=0.5 \mathrm{~mW} \mathrm{~cm}^{-2}\right)$.

In addition to this, the design optimization, intensification or enhancement of the photocatalytic material could be carried out in order to implement more efficient PCO systems for VOC mixture removal $[30,41]$.

\section{Conclusion}

A significant increase in the development of PCO systems for indoor air quality improvement is underway and it seems important to assess PCO system efficiency in experimental conditions closer to real applications. This study focused on the evaluation of the PCO degradation of 
a mixture of three VOCs at ppb level using a continuous closed-loop reactor with a controlled air flow rate. A comparison between PCO degradation experiments conducted with single initial compounds and with a mixture of compounds was made. The main results of the study are:

i.) There is no significant influence on the degradation rate when the compounds are degraded as single initial molecules or when they are initially in a mixture. The slight decrease in the degradation rate is more related to the higher overall initial concentration when compounds are in a mixture.

ii.) There is no observed interaction between the formed intermediates. Intermediates are the same whether compounds are degraded individually or in a mixture. No interaction with chlorinated compounds was highlighted in this case. Molecules are at low concentrations and decane and toluene degradations occur sequentially before TCE degradation leading to no significant impact on the degradation pathway determined in individual conditions.

This study was conducted with only three VOCs in a mixture and our former works have shown that the behavior of VOCs in a mixture cannot be directly extrapolated from single VOC studies. However, it can be noted that when the global VOC concentration is at ppb level, few interactions between either VOCs or intermediates may occur. Further work needs to be done to confirm this point and in future it will be necessary to conduct similar experiments with more complex mixtures.

Finally, it has been demonstrated that oxygenated intermediate compounds, mainly formaldehyde and acetaldehyde, are good representatives of the progress of the degradation process. These molecules could be good indicators in the evaluation of PCO system performance. They can be used for the optimization and design of PCO systems as well as for safety evaluation when these are implemented in buildings. More complete information can be obtained from $\mathrm{CO}_{2}$ formation; however, while this information can potentially be acquired in laboratory environments, this is not the case in real conditions where the $\mathrm{CO}_{2}$ atmospheric content is higher (ppm level) than the formation of $\mathrm{CO}_{2}$ during mineralization.

\section{Acknowledgments}

The authors thank the Institut Carnot Mines for its financial support and Yvan Gouriou, François-Xavier Blanchet and Eric Chevrel for their valuable technical assistance.

\section{References}

1] US EPA, Consumer Product Safety, Commission Office of Radiation and Indoor Air (6604J), The Inside Story: A Guide to Indoor Air Quality, (1995) https://www.epa. gov/indoor-air-quality-iaq/inside-story-guide-indoor-air-quality . (Accessed 30 August 2017)

[2] J. Mo, Y. Zhang, Q. Xu, J.J. Lamson, R. Zhao, Photocatalytic purification of volatile organic compounds in indoor air: a literature review, Atmos. Environ. 43 (2009) 2229-2246, http://dx.doi.org/10.1016/j.atmosenv.2009.01.034.

[3] P. Pichat, Some views about indoor air photocatalytic treatment using TiO2: Conceptualization of humidity effects, active oxygen species, problem of C-1-C-3 carbonyl pollutants, Appl. Catal. B-Environ. 99 (2010) 428-434, http://dx.doi.org/ 10.1016/j.apcatb.2010.07.022.

[4] H. Destaillats, M. Sleiman, D.P. Sullivan, C. Jacquiod, J. Sablayrolles, L. Molins, Key parameters influencing the performance of photocatalytic oxidation (PCO) air purification under realistic indoor conditions, Appl. Catal. B: Environ. 128 (2012) 159-170, http://dx.doi.org/10.1016/j.apcatb.2012.03.014.

[5] S. Wang, H.M. Ang, M.O. Tade, Volatile organic compounds in indoor environment and photocatalytic oxidation: state of the art, Environ. Int. 33 (2007) 694-705 http://dx.doi.org/10.1016/j.envint.2007.02.011.

[6] M. Sleiman, P. Conchon, C. Ferronato, J.-M. Chovelon, Photocatalytic oxidation of toluene at indoor air levels (ppbv): Towards a better assessment of conversion, reaction intermediates and mineralization, Appl. Catal. B-Environ. 86 (2009) 159-165, http://dx.doi.org/10.1016/j.apcatb.2008.08.003.

[7] B. Sanchez, M. Sanchez-Munoz, M. Munoz-Vicente, G. Cobas, R. Portela, S. Suarez, A.E. Gonzalez, N. Rodriguez, R. Amils, Photocatalytic elimination of indoor air biological and chemical pollution in realistic conditions, Chemosphere 87 (2012) 625-630, http://dx.doi.org/10.1016/j.chemosphere.2012.01.050.

[8] N. Costarramone, B. Kartheuser, C. Pecheyran, T. Pigot, S. Lacombe, Efficiency and harmfulness of air-purifying photocatalytic commercial devices: from standardized chamber tests to nanoparticles release, Catal. Today 252 (2015) 35-40, http://dx doi.org/10.1016/j.cattod.2015.01.008.

[9] O. Debono, V. Hequet, L. Le Coq, N. Locoge, F. Thevenet, VOC ternary mixture effect on ppb level photocatalytic oxidation: removal kinetic, reaction intermediates and mineralization, Appl. Catal. B: Environ. 218 (2017) 359-369, http://dx.doi. org/10.1016/j.apcatb.2017.06.070.

[10] AFNOR (Association Française de Normalisation), XP B44-013 - Photocatalysis Test and analysis method for determining the efficacy of photocatalytic systems for eliminating volatile organic compounds/odours in recirculating interior air Confined chamber test, (2009). http://standards.globalspec.com/std/1215220/ afnor-xp-b44-013. (Accessed 30 August 2017).

[11] Y. Luo, D.F. Ollis, Heterogeneous photocatalytic oxidation of trichloroethylene and toluene mixtures in air: kinetic promotion and inhibition, time-dependent catalyst activity, J. Catal. 163 (1996) 1-11, http://dx.doi.org/10.1006/jcat.1996.0299.

[12] C. Xie, Z. Xu, Q. Yang, N. Li, D. Zhao, D. Wang, Y. Du, Comparative studies of heterogeneous photocatalytic oxidation of heptane and toluene on pure titania, titania-silica mixed oxides and sulfated titania, J. Mol. Catal. A: Chem. 217 (2004) 193-201, http://dx.doi.org/10.1016/j.molcata.2004.03.033.

[13] O. Debono, F. Thevenet, P. Gravejat, V. Hequet, C. Raillard, L. Lecoq, N. Locoge, Toluene photocatalytic oxidation at ppbv levels: kinetic investigation and carbon balance determination, Appl. Catal. B: Environ. 106 (2011) 600-608, http://dx.doi. org/10.1016/j.apcatb.2011.06.021.

[14] O. Debono, F. Thévenet, P. Gravejat, V. Héquet, C. Raillard, L. Le Coq, N. Locoge, Gas phase photocatalytic oxidation of decane at ppb levels: removal kinetics, reaction intermediates and carbon mass balance, J. Photochem. Photobiol. A: Chem. 258 (2013) 17-29, http://dx.doi.org/10.1016/j.jphotochem.2013.02.022.

[15] P. Schneider, I. Gebefugi, K. Richter, G. Wolke, J. Schnelle, H.E. Wichmann, J. Heinrich, Indoor and outdoor BTX levels in German cities, Sci. Total Environ. 267 (2001) 41-51, http://dx.doi.org/10.1016/S0048-9697(00)00766-X.

[16] A.T. Hodgson, H. Levin, Volatile Organic Compounds in Indoor Air: A Review of Concentrations Measured in North Americasince 1990, (2003) https://pubarchive. lbl.gov/islandora/object/ir\%3A120436/. (Accessed 30 August 2017).

[17] S.-C. Lee, H. Guo, W.-M. Li, L.-Y. Chan, Inter-comparison of air pollutant concentrations in different indoor environments in Hong Kong, Atmos. Environ. 36 (2002) 1929-1940, http://dx.doi.org/10.1016/S1352-2310(02)00176-0.

[18] G. Li Puma, I. Salvadó-Estivill, T.N. Obee, S.O. Hay, Kinetics rate model of the photocatalytic oxidation of trichloroethylene in air over TiO2 thin films, Sep. Purif Technol. 67 (2009) 226-232, http://dx.doi.org/10.1016/j.seppur.2009.03.011.

[19] T.N. Obee, Photooxidation of sub-parts-per-million toluene and formaldehyde levels an titania using a glass-plate reactor, Environ. Sci. Technol. 30 (1996) 3578-3584, http://dx.doi.org/10.1021/es9602713.

[20] C. Raillard, A. Maudhuit, V. Hequet, L. Le Coq, J. Sablayrolles, L. Molins, Use of experimental designs to establish a kinetic law for a gas phase photocatalytic process, Int. J. Chem. React. Eng. 12 (2014), http://dx.doi.org/10.1515/ijcre-20140012 .

[21] A. Maudhuit, C. Raillard, V. Hequet, L. Le Coq, J. Sablayrolles, L. Molins, Adsorption phenomena in photocatalytic reactions: the case of toluene, acetone and heptane, Chem. Eng. J. 170 (2011) 464-470, http://dx.doi.org/10.1016/j.cej.2011. 02.040 .

[22] É. Dumont, V. Héquet, Determination of the clean air delivery rate (CADR) of photocatalytic oxidation (PCO) purifiers for indoor air pollutants using a closedLoop reactor. Part I: theoretical considerations, Molecules 22 (2017) 407, http://dx. doi.org/10.3390/molecules22030407.

[23] V. Héquet, F. Batault, C. Raillard, F. Thévenet, L. Le Coq, É. Dumont, Determination of the clean air delivery rate (CADR) of photocatalytic oxidation (PCO) purifiers for indoor air pollutants using a closed-loop reactor. part II: experimental results, Molecules 22 (2017) 408, http://dx.doi.org/10.3390/molecules 22030408 .

[24] C.F.H. Allen, The identification of carbonyl compounds by use of 2, 4-dinitophenylhydrazine, J. Am. Chem. Soc. 52 (1930) 2955-2959, http://dx.doi.org/10.1021/ ja01370a058.

[25] T. Salthammer, S. Mentese, R. Marutzky, Formaldehyde in the indoor environment, Chem. Rev. 110 (2010) 2536-2572, http://dx.doi.org/10.1021/cr800399g.

[26] N. Petit, A. Bouzaza, D. Wolbert, P. Petit, J. Dussaud, Photocatalytic degradation of gaseous perchloroethylene in continuous flow reactors: rate enhancement by chlorine radicals, Catal. Today 124 (2007) 266-272, http://dx.doi.org/10.1016/j. cattod.2007.03.050.

[27] M. Hegedús, A. Dombi, Gas-phase heterogeneous photocatalytic oxidation of chlorinated ethenes over titanium dioxide: perchloroethene, Appl. Catal. B: Environ. 53 (2004) 141-151, http://dx.doi.org/10.1016/j.apcatb.2004.05.010.

[28] H.-H. Ou, S.-L. Lo, Photocatalysis of gaseous trichloroethylene (TCE) over TiO2: The effect of oxygen and relative humidity on the generation of dichloroacetyl chloride (DCAC) and phosgene, J. Hazard. Mater. 146 (2007) 302-308, http://dx.doi.org/ 10.1016/j.jhazmat.2006.12.039.

[29] F. Batault, V. Héquet, C. Raillard, F. Thévenet, N. Locoge, L. Le Coq, How chemical and physical mechanisms enable the influence of the operating conditions in a photocatalytic indoor air treatment device to be modeled, Chem. Eng. J. 307 (2017) 766-775, http://dx.doi.org/10.1016/j.cej.2016.08.118.

[30] T. Van Gerven, G. Mul, J. Moulijn, A. Stankiewicz, A review of intensification of photocatalytic processes, Chem. Eng. Process. Process Intensif. 46 (2007) 781-789, http://dx.doi.org/10.1016/j.cep.2007.05.012.

[31] T. Guo, Z. Bai, C. Wu, T. Zhu, Influence of relative humidity on the photocatalytic oxidation (PCO) of toluene by TiO2 loaded on activated carbon fibers: PCO rate and 
intermediates accumulation, Appl. Catal. B: Environ. 79 (2008) 171-178, http://dx. doi.org/10.1016/j.apcatb.2007.09.033.

[32] J. Shang, Y.G. Du, Z.L. Xu, Photocatalytic oxidation of heptane in the gas-phase over TiO2, Chemosphere 46 (2002) 93-99, http://dx.doi.org/10.1016/S0045-6535(01) 00115-1.

[33] M.R. Nimlos, W.A. Jacoby, D.M. Blake, T.A. Milne, Direct mass spectrometric studies of the destruction of hazardous wastes. 2. Gas-phase photocatalytic oxidation of trichloroethylene over titanium oxide: products and mechanisms, Environ. Sci. Technol. 27 (1993) 732-740, http://dx.doi.org/10.1021/es00041a018.

[34] P.B. Amama, K. Itoh, M. Murabayashi, Photocatalytic degradation of trichloroethylene in dry and humid atmospheres: role of gas-phase reactions, J. Mol. Catal. A: Chem. 217 (2004) 109-115, http://dx.doi.org/10.1016/j.molcata.2004. 03.016.

[35] K. Demeestere, A.D. Visscher, J. Dewulf, M.V. Leeuwen, H.V. Langenhove, A new kinetic model for titanium dioxide mediated heterogeneous photocatalytic degradation of trichloroethylene in gas-phase, Appl. Catal. B: Environ. 54 (2004) 261-274, http://dx.doi.org/10.1016/j.apcatb.2004.06.020.

[36] S.-K. Joung, T. Amemiya, M. Murabayashi, R. Cai, K. Itoh, Chemical adsorption of phosgene on $\mathrm{TiO} 2$ and its effect on the photocatalytic oxidation of trichloroethylene, Surf. Sci. 598 (2005) 174-184, http://dx.doi.org/10.1016/j.susc. 2005.08.037.

[37] K.H. Wang, J.M. Jehng, Y.H. Hsieh, C.Y. Chang, The reaction pathway for the heterogeneous photocatalysis of trichloroethylene in gas phase, J. Hazard. Mater. 90 (2002) 63-75, http://dx.doi.org/10.1016/S0304-3894(01)00331-4.

[38] A.T. Hodgson, H. Destaillats, D.P. Sullivan, W.J. Fisk, Performance of ultraviolet photocatalytic oxidation for indoor air cleaning applications, Indoor Air 17 (2007) 305-316, http://dx.doi.org/10.1111/j.1600-0668.2007.00479.x.

[39] W. Chen, J. Zhang, Photocatalytic oxidation of multi-component systems - an investigation using toluene/ethylbenzene, octane/decane/dodecane and formaldehyde/acetaldehyde, J. Adv. Oxid. Technol. 11 (2008) 163-173.

[40] O. d'Hennezel, D.F. Ollis, Trichloroethylene-Promoted photocatalytic oxidation of air contaminants, J. Catal. 167 (1997) 118-126, http://dx.doi.org/10.1006/jcat. 1997.1552.

[41] L. Ren, M. Mao, Y. Li, L. Lan, Z. Zhang, X. Zhao, Novel photothermocatalytic synergetic effect leads to high catalytic activity and excellent durability of anatase TiO2 nanosheets with dominant $\{001\}$ facets for benzene abatement, Appl. Catal. B Environ. 198 (2016) 303-310, http://dx.doi.org/10.1016/j.apcatb.2016.05.073. 